\title{
Heterochromatin differentiation between two species of the genus Dociostaurus (Orthoptera: Acrididae)
}

\author{
E. RODRIGUEZ IÑIGO, J. L. BELLA \& C. GARCÍA DE LA VEGA* \\ Unidad de Genética, Departamento de Biología, Edificio de Biologia, Facultad de Ciencias, Universidad Autónoma de \\ Madrid, 28049 Madrid, Spain
}

\begin{abstract}
Dociostaurus jagoi and Dociostaurus genei are two acridoid grasshoppers which show large differences in heterochromatin content. The use of several banding techniques, including fluorochrome staining and restriction endonuclease digestion, provides further information on the characteristics of the constitutive heterochromatin regions revealed with the $\mathrm{C}$-banding method. Thus both species show GC-enriched bands accompanying active nucleolar organizers which differ in location. Because of its bright response to DAPI and CMA3, the centromeric heterochromatin seems to have a bipartite nature in terms of DNA composition in $D$. genei, while it shows dull staining with both fluorochromes in D. jagoi. However, two endonucleases, MboI and Sau3A, extensively digest these regions in both species. The supernumerary heterochromatic segments present only in $D$. genei seem to be AT-rich and are extensively digested with AluI. These results reveal heterogeneity in the distinct $\mathrm{C}$-banded regions which, in turn, are equilocally distributed in both chromosome complements.
\end{abstract}

Keywords: chromosome banding, Dociostaurus, insect cytogenetics, supernumary heterochromatin.

\section{Introduction}

Constitutive heterochromatin, usually revealed by C-banding techniques, is a common component of eukaryotic genomes that presents large variation in content and distribution both between and within species (John, 1988). Other banding techniques, such as fluorochrome staining or digestion with restriction enzymes, have revealed that heterochromatin may show important differences in composition (heterogeneity) and it is commonly restricted to certain chromosome regions within a given complement (equilocality). In Acridoid grasshoppers, general surveys of Iberian (Santos et al., 1983) and Australian (King \& John, 1980) grasshoppers demonstrated dramatic changes in heterochromatin content and distribution even between closely related species. $D$. jagoi and $D$. genei are two species widely distributed in drylands of south-western Europe, North Africa and the Middle East. They are commonly found in sympatry. On morphological grounds these species were considered as a single one up to 1978 , when

${ }^{*}$ Correspondence.
Soltani (1978) described sharp differences in male genitalia and number of stridulatory pegs. In this paper we report chromosome differentiation between both species, mainly involving the heterochromatin content. Moreover we have assayed several banding techniques to further characterize the different heterochromatic regions. Results obtained support two common features of heterochromatin: heterogeneity and equilocality.

\section{Material and methods}

Adult males of $D$. jagoi and $D$. genei collected from natural populations in central Spain were dissected and the testes fixed in ethanol:acetic acid (3:1). To carry out the different banding techniques squash preparations were performed in a drop of acetic acid 45 per cent, the coverslips were removed after freezing in liquid nitrogen and the slides were then air-dried. C-banding was performed according to LópezFernández \& Gosálvez (1981). The silver impregnation method was that developed by Rufas \& Gosálvez (1982). Fluorochrome banding with 4,6 diamidin 2 
phenylindole (DAPI), distamycin A (DA) and chromomycin A3 (CMA3) was obtained according to Schweizer (1980). In situ digestion with restriction enzymes (REs) was carried out according to Mezzanotte et al.(1983).

\section{Results}

The chromosome complement of both species is composed of 23 (males) and 24 (females) acro-telocentric chromosomes. According to their size they can be grouped in three long (L1-L3), five medium (M4-M8) and three short (S9-S11) pairs. The $\mathrm{X}$ chromosome, single in males $(\mathrm{XO})$ and double in females $(\mathrm{XX})$, is the 4th in decreasing size (García de la Vega, 1984).

\section{Ag-NORs}

Throughout the first meiotic prophase two nucleoli are observed in both species. However their chromosome location is clearly distinct. In $D$. jagoi the nucleolar remnants appear associated to an interstitial region of the L1 bivalent, and the centromere region of a short bivalent (Fig. 1a), while in $D$. genei nucleoli are associated to the centromeric region of the two short bivalents (Fig. 1b).

\section{C-banding patterns}

In both species every chromosome shows pericentromeric C-bands. However, these bands are larger in $D$.

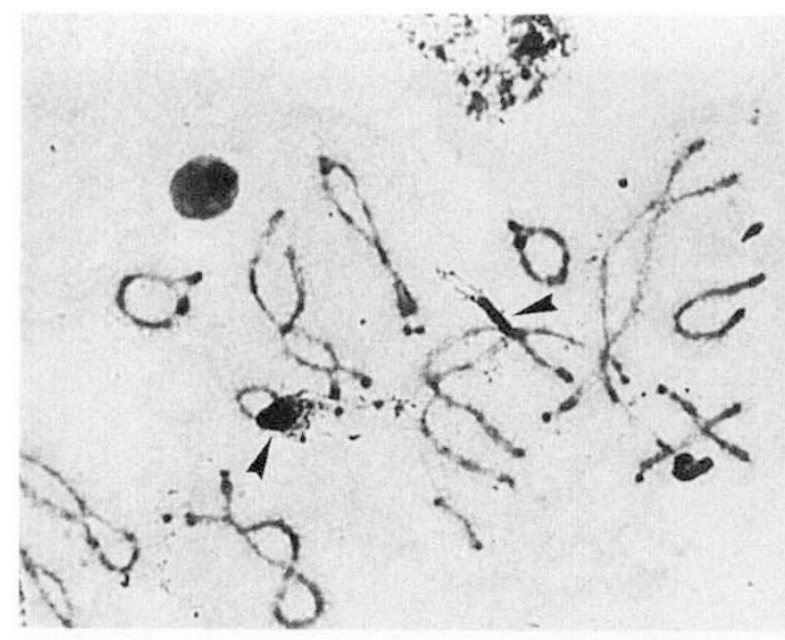

a
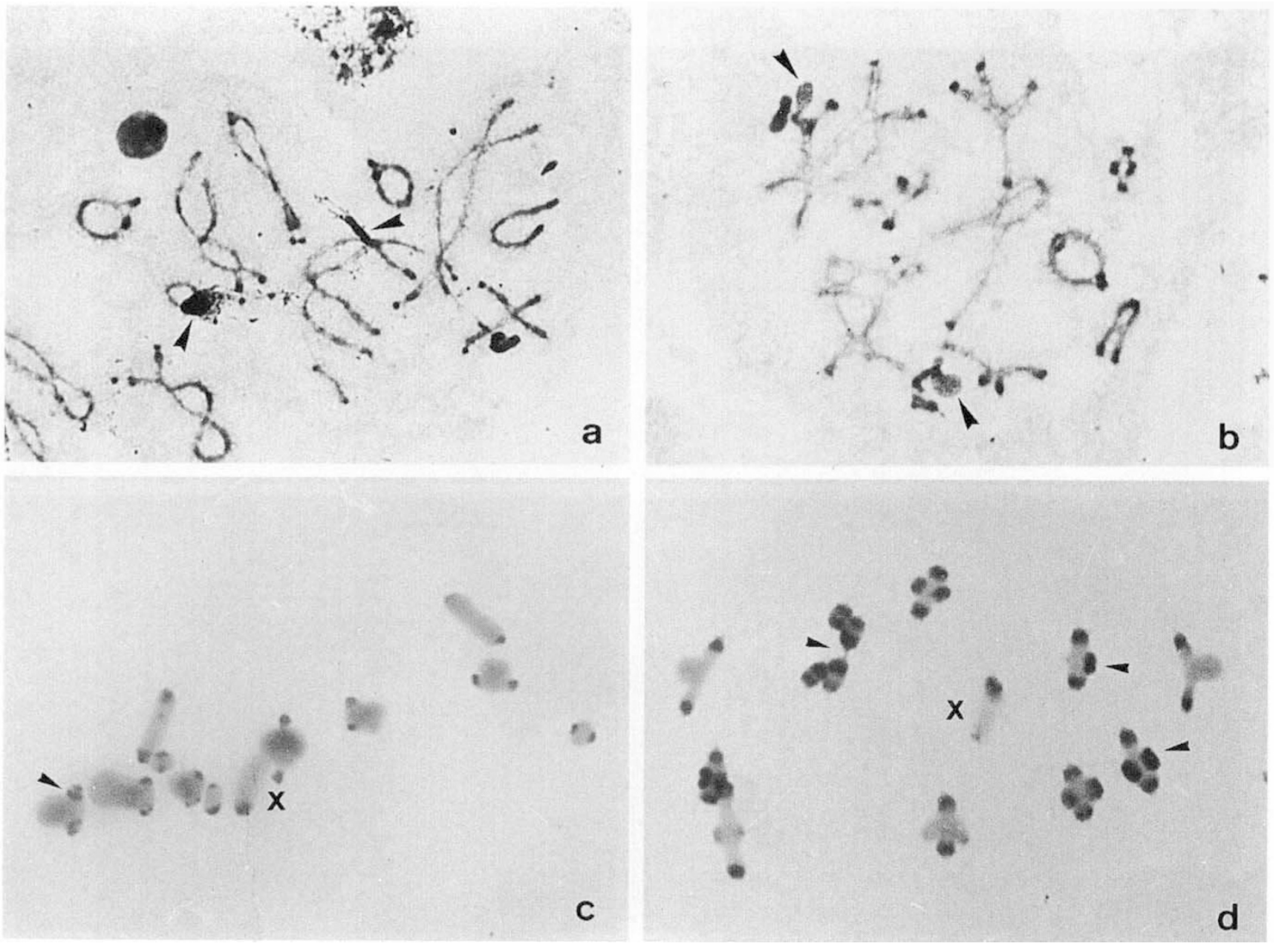

Fig. 1 (a) and (b) Silver-stained diplotene cells of D. jagoi (a) and D. genei (b) showing two active NORs in both cases but with different location (arrows). (c) and (d) C-banded first meiotic metaphases of D. jagoi (c) and D. genei (d). Every chromosome has pericentromeric bands although those of $D$. genei are bigger than those of $D$. jagoi. In this species the L1 bivalent has an interstitial band (arrow). Moreover most of the autosomes of D. genei have distal supernumerary segments (arrows). X: sex chromosome. 
genei than those found in D. jagoi (cf. Fig. 1c and d). Moreover seven chromosome pairs (M5-S11) of $D$. genei may show large distal heterochromatic blocks (Fig. 1d). At least five of the pairs show polymorphism for the presence of these supernumerary segments. The regions where NORs have been detected also show accompanying $\mathrm{C}$-bands. This is particularly obvious in the case of the L1 pair of D. jagoi where an interstitial band is always present (Fig. 1c). The C-bands associated with the other active NORs of both species are closely located to the centromeric bands of the corresponding chromosomes.

\section{Fluorochrome banding patterns}

Centromere heterochromatin of both species can be differentiated when fluorochromes specific for AT (DAPI) or GC (Chromomycin A3) DNA base pair enriched regions are assayed. Neither fluorochrome reveals bright bands in the centromere regions of $D$. jagoi (Fig. 2a and c), whereas the centromeric C-bands of D. genei show complex composition (cf. Figs 1d, $2 \mathrm{~b}$ and d). Thus the proximal region appears bright with DAPI (Fig. 2b), while DA-CMA3 reveals tiny juxtacentromeric bands below those differentially stained with DAPI in most of the chromosomes (Fig. 2d). The supernumerary segments present in $D$. genei are enriched in AT regions, as revealed by the bright bands obtained with DAPI. These regions, in turn, appear negative with DA-CMA3 (cf. Fig. $2 b$ and d). Finally, the heterochromatin associated with active NORs appears bright with DA-CMA3 in both species (Fig. 2c and d).

\section{Restriction endonuclease banding patterns}

Chromosomes of both species were digested in situ with several REs (Tables 1 and 2). Most of the enzymes employed reproduce $\mathrm{C}$-like banding patterns; that is,
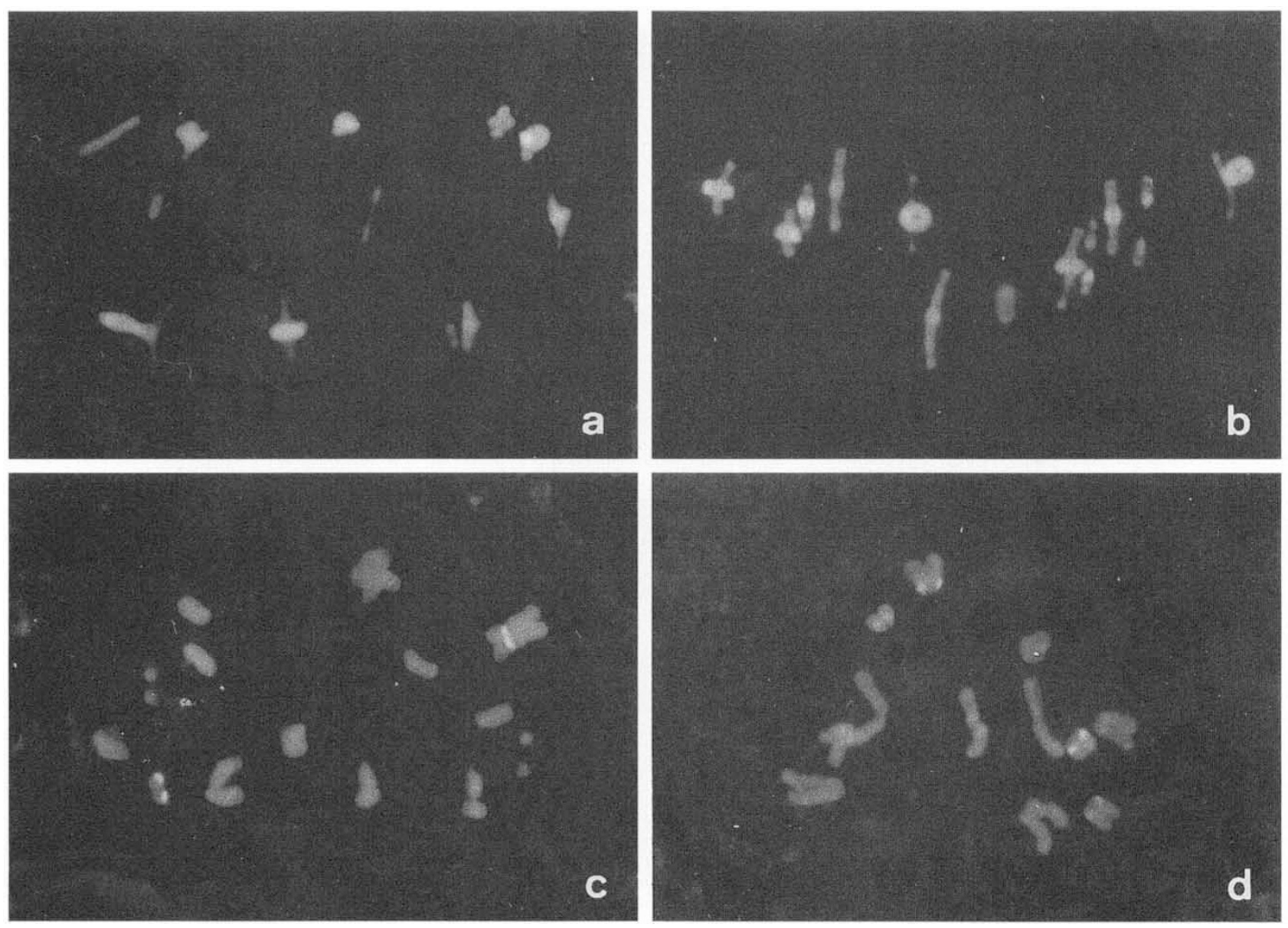

Fig. 2 Fluorochrome banding. (a) and (b) First metaphases of D. jagoi (a) and D. genei (b) stained with DAPI. Both the centromeres and the distal segments of $D$. genei (b) appear bright. In $D$. jagoi (a) C-banded regions show dull fluorescence. Second metaphases of $D$. jagoi $(\mathrm{c})$ and $D$. genei (d) stained with DA-CMA3. In D. jagoi two half-bivalents show bright bands that correspond with the active NORs detected with silver staining. Some chromosomes of $D$. genei show paracentromeric positive bands. In this species neither the centromeric regions nor the distal blocks show bright fluorescence. 
Table 1 Characterization of the heterochromatic regions of D. jagoi

\begin{tabular}{llc}
\hline & NORs & CEN \\
\hline C-banding & + & + \\
DAPI & - & 0 \\
DA-CMA3 & + & 0 \\
REs & & \\
AluI (AG/CT) & & + \\
BamHI (G/GATCC) & + & + \\
DraI (TTT/AAA) & + & + \\
EcoRI (G/AATTC) & + & + \\
Haell (GG/CC) & + & + \\
HpaII (C/CGG) & - & + \\
Hinfl (G/ANTC) & - & - \\
Mbol (/GATC) & + & \\
Sau3A (/GATC) & 0 & + \\
\hline
\end{tabular}

NORs: nucleolar organizer regions; CEN: pericentromeric regions. + : positive staining; - : negative staining; 0 : dull staining.

chromosome arms are extensively digested except where constitutive heterochromatin regions occur. However, some of them have provided clear-cut differences between the heterochromatic regions. Thus HaeIII and HpaII, two enzymes containing only $\mathrm{G}$ and $\mathrm{C}$ in their targets, digest extensively the $\mathrm{G} / \mathrm{C}$ enriched regions of both complements, i.e. the heterochromatin associated with NORs as well as the juxtacentromeric bands of several chromosomes in D. genei (Fig. 3a and $b$ ).

The isoschyzomeres $M b o I$ and Sau3A digest the centromeric regions of both species while, to a large extent, they do not affect the distal blocks of $D$. genei (Fig. $3 \mathrm{c}$ and d). On the contrary, AluI produces intensive digestion in the supernumerary blocks while its effect on the centromeric heterochromatin of $D$. genei and D. jagoi is negligible (Fig. 4). Interestingly, PvuII, a six-base cutter that contains the target of $A l u \mathrm{I}$, reproduces the C-banding pattern in both species and does not produce intensive digestion in the supernumerary segments (Fig. 4a).

\section{Discussion}

E. Heitz gave the name heterochromatin to those chromosome regions that do not undergo decondensation throughout the cell cycle. He also pointed out that these regions occupy similar positions in the chromosomes of a given complement, i.e. they show equilocal distribution (Heitz, 1933, 1935). Derived models
Table 2 Characterization of the heterochromatic regions of D. genei

\begin{tabular}{lllll}
\hline & & & \multicolumn{2}{c}{ CEN } \\
\cline { 3 - 5 } & NORs & PROX & JUXTA & SS \\
\hline C-banding & + & + & + & + \\
DAPI & - & + & 0 & + \\
DA-CMA3 & + & 0 & + & 0 \\
REs & & & & \\
AluI (AG/CT) & + & + & + & + \\
BamHI (G/GATCC) & + & + & + & + \\
DraI (TTT/AAA) & + & + & + & + \\
EcoRI (G/AATTC) & + & + & + & + \\
HaeII (GG/CC) & - & + & - & + \\
HpaII (C/CGG) & - & + & - & + \\
Hinf (G/ANTC) & + & + & + & + \\
MboI (/GATC) & 0 & - & - & + \\
Sau3A (/GATC) & 0 & - & - & + \\
PviII (CAG/CTG) & + & + & + & + \\
\hline NORs & & & & \\
\hline
\end{tabular}

NORs: nucleolar organizer regions; CEN: pericentromeric regions. PROX: proximal regions; JUXTA: juxtacentromeric regions: SS: supernumerary segments.

+ : positive staining; - : negative staining; 0 : dull staining.

assume the concerted evolution of similar repetitive DNA sequences in equivalent chromosome arms at similar positions (Schweizer et al., 1983; Schweizer \& Loidl, 1987). A comparative study of heterochromatin distribution and heterogeneity in 10 species of acridoid grasshoppers showed the strong tendency within a given complement for the accumulation of heterochromatin with similar composition at similar sites, while different sites within a given complement usually show different compositional properties (John et al., 1985). This regularity is exemplified by the tendency in these and some other organisms to show differences in composition between centric and distal C-bands. Moreover, different but related species may show distinct heterochromatin composition at equilocal sites (John et al., 1985; Schweizer et al., 1987).

Our results on the chromosome complements of $D$. jagoi and $D$. genei support this position (Tables 1 and 2 ). In fact, the equilocal distribution extends to some other characteristics since certain heterochromatin regions within a complement are different, while those located in homologous positions behave in identical manner after distinct treatments. This is well illustrated in $D$. genei where centromeric and distal heterochromatin are easily distinguishable when chromosomes are digested with $A l u \mathrm{I}$ and the isoschyzomeres 

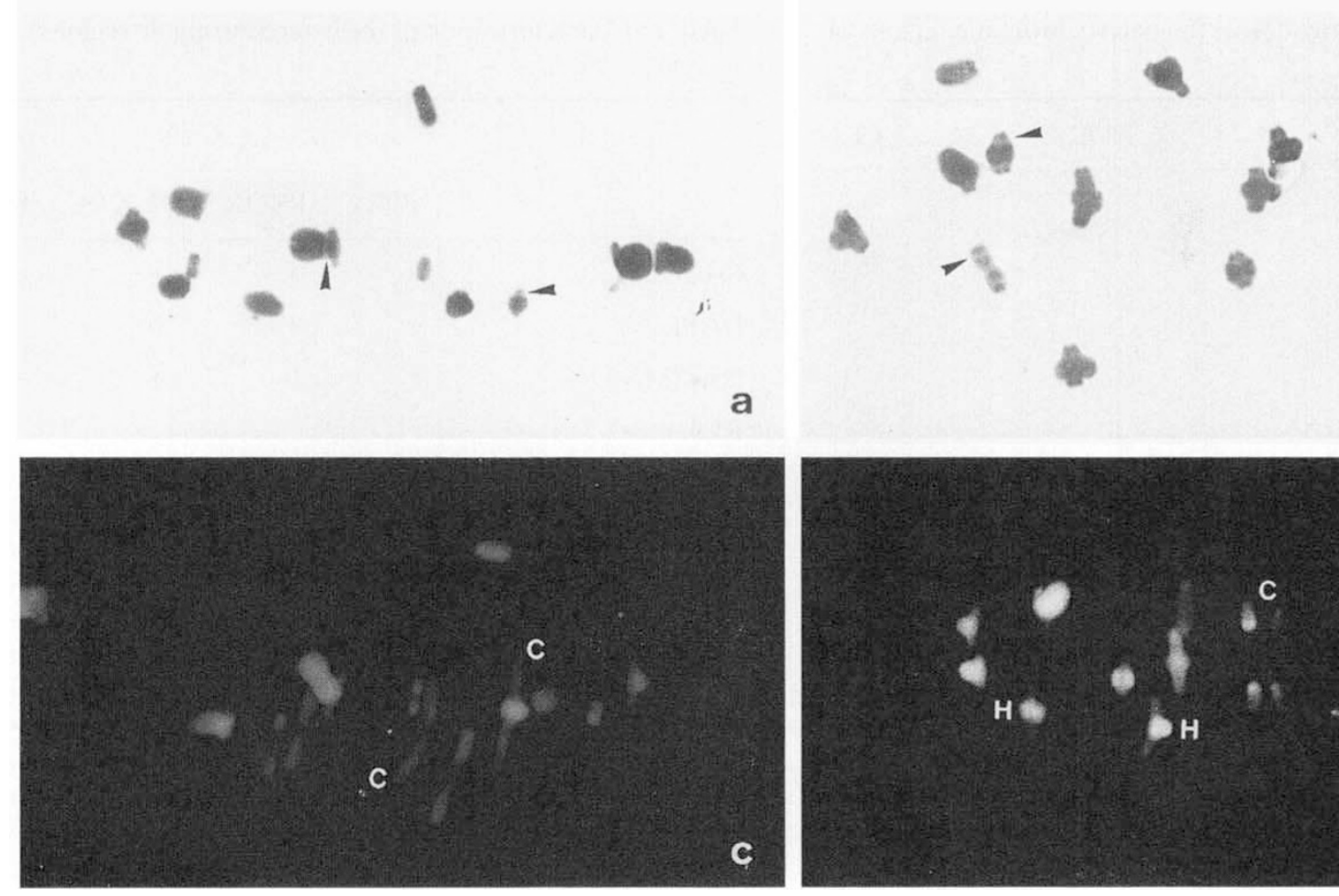

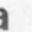

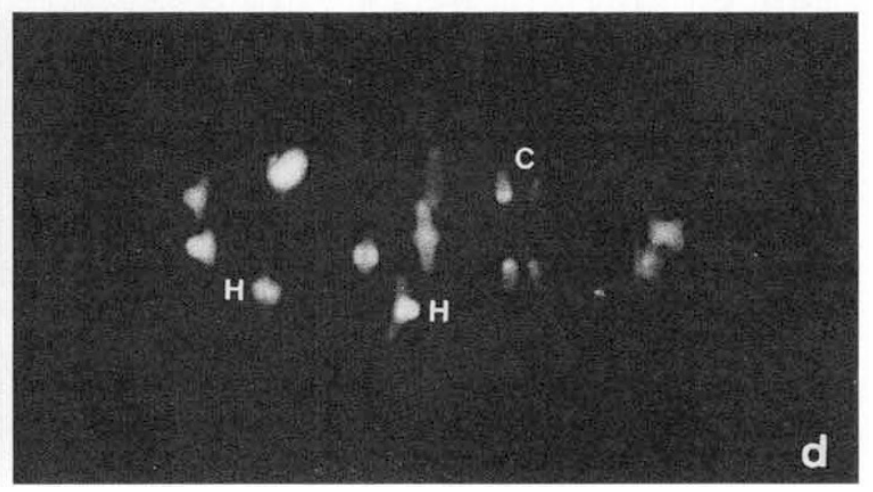

Fig. 3 Restriction endonuclease banding patterns. (a) and (b) First meiotic metaphases of D. jagoi (a) and D. genei (b) after digestion with Haelll and stained with Giemsa. Most of the chromatin is resistant to this enzyme. Clear-cut differentiation due to extensive digestion (arrows) is obtained in those regions that are positive to CMA3 staining. (c) and (d) First meiotic metaphases of D. jagoi (c) and D. genei $(\mathrm{d})$ after digestion with Sau $3 \mathrm{~A}$ and stained with ethidium bromide. In both cases the centromeric heterochromatin $(\mathrm{c})$ is extensively digested, while the distal blocks $(\mathrm{H})$ of $D$. genei are resistant to the attack of this endonuclease.

MboI and Sau3A (see Fig. 4). Since these enzymes produce extensive digestion in particular regions, i.e. $\mathrm{Mbol}$ and $S a u 3 \mathrm{~A}$ in the centromeric regions and $A l u \mathrm{I}$ in the supernumerary segments, we can assume that in both cases those C-bands must contain highly repetitive DNA sequences which include the corresponding target. Similar results where repetitive sequences are detected after digesting chromosomes with REs have been reported in both plant and animal species (see references in López-Fernández et al., 1991).

On the other hand, the combined use of fluorochrome banding and in situ restriction endonuclease digestion shows large heterogeneity among presumed similar C-banded regions (see Table 1 and 2). Thus: (i) the heterochromatin associated with the NORs seems to be similar in both species. It shows DA-CMA3 positive response indicating $\mathrm{GC}$ richness, which is a common feature of this kind of heterochromatin in distinct species of plants and animals (Deumling \& Greilhuber, 1982; John et al., 1985; Schweizer et al., 1983; Gosálvez et al., 1987; López-Fernández et al., 1989). However, these regions are neither always digested with restriction endonucleases whose target only con- tains G and C, e.g. HaeIII (Gosálvez et al., 1987; López-Fernández et al., 1989), nor revealed with specific banding techniques such as the N-banding (Fox \& Santos, 1985); (ii) both species show pericentromeric heterochromatin which is different both in size and DNA base composition. $D$. jagoi does not show any response after DA-CMA3 or DAPI, while D. genei with bigger $\mathrm{C}$-bands shows positive response after DAPI in all these regions and DA-CMA3 positive response in some of them. Interestingly, in both species the restriction enzymes assayed produce similar results. Thus, in spite of being different, they still share the targets for some of the REs, i.e.: $M b o I$ and Sau3A; (iii) this situation differs from that found in the distal supernumerary heterochromatic segments which are exclusive to $D$. genei. In this case the heterochromatin seems to be quite different from that situated in the pericentromeric regions of both species. This may mean a distinct origin possibly because of an amplification of sequences resident in these distal areas of $D$. genei. This situation coincides with the hypothesis of telomeric regions as C-band initiation sites (Greilhuber \& Loidl, 1983; Schweizer \& Loidl, 1987). 


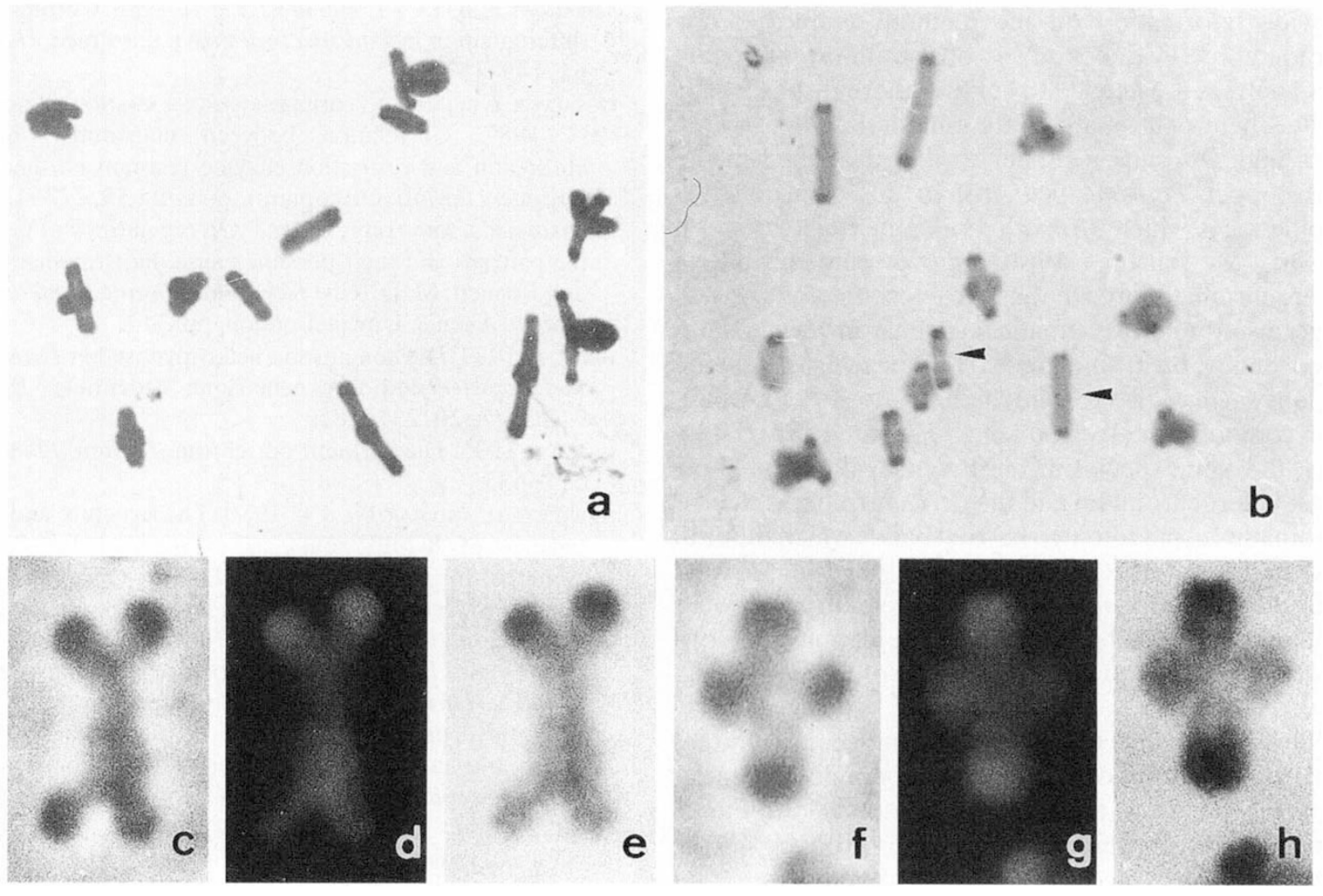

Fig. 4 Restriction endonuclease banding patterns. (a) and (b) First meiotic metaphases of $D$. genei after digestion with $P v u I I$ (a) and $A l u \mathrm{I}(\mathrm{b})$ and stained with Giemsa. Pvull reproduces the C-banding in this species. Both centromeric and distal segments are resistant to this enzyme. However, $A l u \mathrm{I}$, whose target is included in that of $P v u \mathrm{II}$, provokes extensive digestion of the heterochromatic segments (arrows). (c)-(h) selected bivalents of $D$. genei after digestion with $\operatorname{Sau} 3 \mathrm{~A}(\mathrm{c})-(\mathrm{e})$ and $A l u \mathrm{I}(\mathrm{f})-(\mathrm{h})$ to show the complementary effect of these enzymes on the heterochromatin of $D$. genei. (c) and (f) phase contrast; (d) and (g) ethidium bromide staining; (e) and (h) Giemsa staining.

In summary, our results show the existence of clear karyotypic differentiation between both species revealed not only by the four different classes of heterochromatin found (see Tables 1 and 2), but also by the existence of extra heterochromatic segments distally placed in $D$. genei. This is particularly interesting since these grasshoppers are commonly found in sympatric populations and their exophenotypic characteristics are roughly similar (Soltani, 1978). Previous reports on chromosome characteristics of these species (Santos et al., 1983; Navas-Castillo et al., 1986) did not take into account the taxonomic differences and have been erroneously attributed to $D$. genei when they agree with the data here reported for $D$. jagoi.

There are many other examples where closely related species with very similar karyotypes differ to a large extent in the heterochromatin content (John \&
King, 1983). Although some authors have proposed that these differences could be involved in species divergence (Nagl, 1978), this assumption has been criticized (John \& Miklos, 1979; John \& King, 1983). In our case the karyotypic differences between $D$. genei and $D$. jagoi show that the chromosomal divergence occurred during their speciation. After extensive sampling and chromosome characterization carried out in different Spanish populations we have not yet found any hybrid individuals.

Unfortunately information on the chromosome characteristics of both species in other regions of their geographical distribution is scarce. Soltani (1978) reported the presence of "terminal heterochromatic segments" in $D$. genei and also in $D$. jagoi from Israel. This could mean that the supernumerary heterochromatin is present in both species in the easternmost region of their range. However, this author does not 
provide information on the methods employed nor photographic evidence of his observations. Thus further analyses are needed to confirm these results.

The heterochromatin differentiation shown by $D$. jagoi and $D$. genei is similar to that described in the grasshopper Podisma pedestris. In this case, the two Alpine races which form a hybrid zone (for review see Hewitt \& Barton, 1980) show pericentromeric heterochromatin in all the chromosomes as well as large distal heterochromatic segments in the medium sized and sex chromosomes. These heterochromatic regions seem to be GC-enriched in terms of DNA base pair composition (Westerman \& Hewitt, 1985). However, the same species in the Pyrenees does not show distal heterochromatin and the pericentromeric heterochromatin is split into two narrow bands which differ in base pair richness (Gosálvez et al., 1988). Since viable hybrids between Pyrenean and Alpine individuals were obtained in the laboratory, these populations are considered to belong to distinct chromosomal races (Bella et al., 1990, 1991).

Thus the existence of similar chromosomal differentiation in systems of dissimilar taxonomic categories supports the view that the chromosomal differences here described were not causally involved in the divergence of $D$. jagoi and $D$. genei, although they constitute excellent chromosome markers for differentiating the species.

\section{Acknowledgements}

This work has been supported by grants awarded by Comisión Interministerial Científica y Técnica (Spain) (PB90-0192) and European Community (SCI-01276).

\section{References}

BELLA. J. L., GOSALVEZ, J., LOPEZ-FERNANDEZ, C., GARCIA DE LA VEGA, C., NICHOLS, R. A. AND HEWITT, G. M. 1990. Chromosome divergence in Podisma through the Alps, Pyrenees and Sistema Ibérico. Bol. San. Veg., 20, 349-358.

BELLA, J. L., WESTFRMAN, M., LOPEZ-FERNANDEZ, C., DE LA TORRE, J., RUBIO, J. M. AND GOSAlveZ, J. 1991. Sex chromosome and autosomes divergence in Podisma (Orthoptera) through West Meridional Europe. Genet., Sel., Evol., 23, 6-13.

DEUMLING, B. AND GREILHUBER, J. 1982. Characterization of the heterochromatin in different species of the Scilla siberica group (Liliaceae) by in situ hybridization of satellite DNAs and fluorochrome banding. Chromosoma, 84, 535-555.

FOX, D. P. AND SANTOS, J. L. 1985. N-bands and nucleolus expression in Schistocerca gregaria and Locusta migratoria. Heredity, 54, 333-341.

GARCIA DE LA VEGA, C. 1984. Distribución de la heterocromatina en algunas especies de acrídidos de la fauna española. Ph.D Thesis, Universidad Autónoma de Madrid, Madrid.
GoSAlvez, J., Bella, J. L. AND HewitT, G. M. 1988. Chromosomal differentiation in Podisma pedestris: a third race. Heredity, 61, 149-157.

GOSALVEZ, J., BELLA, J. L., LOPEZ-FERNANDEZ, C. AND MEZZANOTTE, R. 1987. Correlation between constitutive heterochromatin and restriction enzyme resistant chromatin in Arcyptera tornosi (Orthoptera). Heredity, 59, 173-180.

GREILHUBER, J. AND LOIDL, J. 1983. On regularities of C-banding patterns and their possible cause. In: Brandham, P. E. and Bennett, M. D. (eds) Kew Chromosome Conference II, George Allen \& Unwin, London, pp. 344.

HEITZ, E. 1933. Die somatisone heteropynose bei Drosophila melanogaster und ihre genetisone bedentung. Biol. Z. Zellforsch, 20, 237-287.

HEITZ, E. 1935. Die herkunft der chromozentren. Planta, 18, $517-635$.

HEWITT, G. M. AND BARTON, N. H. 1980. The structure and maintenance of hybrid zones as exemplified by Podisma pedestris. In: Blackman, R. L., Hewitt, G. M. and Ashburner, M. (eds) Insect cytogenetics, Blackwell Scientific Publications, Oxford, pp. 149-170.

JOHN, B. 1988. The biology of heterochromatin. In: Verma, R. S. (ed.) Heterochromatin, Cambridge University Press, Cambridge, pp. 1-147.

JOHN, B. AND KING, M. 1983. Populations cytogenetics of Atractomorpha similis I. C-band variation. Chromosoma, 88, 57-68.

JOHN, B. AND MIKLOS, G. L. G. 1979. Functional aspects of satellite DNA and heterochromatin. Int. Rev. Cytol., 58, $1-114$.

JOHN, B., KING, M., SCHWEIZER, D. AND MENDELAK, M. 1985. Equilocality of heterochromatin distribution and heterochromatin heterogeneity in acridoid grasshoppers. Chromosoma, 91, 185-200.

KING, M. AND JOHN, B. 1980. Regularities and restrictions governing $\mathrm{C}$ band variation in acridoid grasshoppers. Chromosoma, 76, 123-150.

LOPEZ-FERNANDFZ. C. AND GOSALVEZ, J. 1981. Differential staining of a heterochromatic zone in Arcyptera fusca (Orthoptera). Experientia, 37, 240.

LOPEZ-FERNANDEZ, C., GOSALVEZ, J., FERRUCCI, L. AND MEZZANOTTE, R. 1991. Restriction endonucleases in the study of eukaryotic chromosomes. Genetica, 83, $257-274$.

LOPEZ-FERNANDEZ, C., GOSALVEZ. J. AND MEZZANOTTE, R. 1989. Heterochromatin heterogeneity in Oedipoda germanica (Orthoptera) detected by in situ digestion with restriction endonucleases. Heredity, 62, 269-277.

MEZZANOTTE, R., BIANCHI, U., VANNI, R. AND FERRUCCI, L. 1983. Chromatin organization and restriction endonucleases activity on human metaphase chromosomes. Cytogenet. Cell Genet., 36, 562-566.

NAGL, w. 1978. Endopoliploidy and Polyteny in Differentiation and Evolution, North-Holland Publ., Amsterdam.

NAVAS-CASTILlO, J., CABRERO, J. AND CAMACHO, J. P. M. 1986. $\mathrm{C}$-banding response of seven supernumerary segments in grasshoppers. Cytobios, 47, 107-113.

RUFAS, J. S. AND GOSAlvez, J. 1982. Development of silver stained structures during spermatogenesis of Schistocerca 
gregaria (Forsk) (Orthoptera: Acrididae). Caryologia, 35, 261-267.

SANTOS, J. L., ARANA, P. AND GiRALDEZ, R. 1983. Chromosome banding patterns in Spanish Acridoidea. Genetica, 61, $65-74$.

SCHWEIZER, D. 1980. Simultaneous fluorescent staining of R-bands and specific heterochromatic regions (DA/DAPI bands) in human chromosomes. Cytogenet. Cell Genet., 27, 190-193.

SCHWEIZER, D. AND LOIDL, J. 1987. A model for heterochromatin dispersion and the evolution of C-band patterns. In: Stahl, A., Luciani, J. M. and Vagner-Capodano, A. M. (eds) Chromosomes Today, 9, Allen \& Unwin, London, pp. 61-74.
SCHWEIZER, D., LOIDL, J. AND HAMILTON, B. 1987. Heterochromatin and the phenomenon of chromosome banding. In: Hennig, W. (ed.) Structure and Function of Eukaryotic Chromosomes, Springer-Verlag, Berlin, pp. 235-254.

SCHWEIZER, D., MENDELAK, M., WHITE, M. J. D. AND CONTRERAS, N. 1983. Cytogenetics of the parthenogenetic grasshopper Warramaba virgo and its bisexual relatives. X. Patterns of fluorescent banding. Chromosoma, 88, 227-236.

SOLTANI, A. A. 1978. Preliminary synonymy and description of new species in the genus Dociostaurus Fieber, 1853 (Orthoptera: Acridoidea; Gomphocerinae) with a key to the species in the genus. J. Ent. Soc. Iran., Supp. 2, 3-93. WESTERMAN, M. AND HEWITT, G. M. 1985. Chromosome banding in Podisma pedestris. Heredity, 55, 157-161. 